\title{
Classes sociais, RELAÇÕES DE CLASSE E TRABALHO: POLÍTICA E TEORIA
}

\author{
Henrique Amorim ${ }^{1}$, Simone Wolff ${ }^{2}$ \\ e Filipe Raslan ${ }^{3}$
}

$\mathrm{N}$ a célebre passagem do Manifesto do Partido Comunista (1848): "A história de toda sociedade até hoje é a história de luta de classes" (1996, p. 66) podemos notar o peso histórico da luta de classes e das classes sociais e a relevância teórica do tema para Karl Marx e Friedrich Engels. Só isso já nos valeria um dossiê concentrado na discussão das classes sociais e do trabalho. Não obstante, devemos fugir de um suposto argumento de autoridade e refletirmos sobre os problemas sociais concretos que figuram como síntese das relações de classe nas sociedades capitalistas contemporâneas.

A relevância empírica do conjunto de relações sociais que conformam as classes sociais, sua existência, sua forma de produção e reprodução sociais e, por isso, o trabalho assalariado como atividade que produz e reproduz as classes sociais, deram sentido à organização desse Dossiê.

Uma profusão de teses e de teorias sociológicas foi desenvolvida a partir dos anos 1970 com o objetivo de superar a análise marxista das classes sociais entendida como uma análise específica da indústria, isto é, ancorada no "paradigma produtivo". De início, portanto, é necessário definir o que seria esse paradigma produtivo e qual seria o diálogo do marxismo com este paradigma para o conjunto dessas teses.

\footnotetext{
${ }^{1}$ Doutor em Ciências Sociais pela UNICAMP e professor de Sociologia do Depto. de Ciências Sociais da Universidade Federal de São Paulo (Campus Guarulhos). henriqueamorim@hotmail.com

${ }^{2}$ Doutora em Ciências Sociais pela UNICAMP, docente do Depto. de Ciências Sociais da Universidade Estadual de Londrina.wolff.simone@gmail.com

${ }^{3}$ Doutorando em Sociologia pela UNICAMP. fraslan@hotmail.com
} 
As teses que indicam o marxismo como uma teoria específica do industrialismo, a qualificam como economicista. Tratar-se-ia de uma análise que tem seu foco na produção (na esfera da economia) e que, por isso, não contemplaria outras esferas significativas da sociedade como a cultura, por exemplo. Sendo uma análise típica da indústria, o marxismo explicitaria as formas de sociabilidade existentes até o momento em que a produção de mercadorias na indústria fosse central. Superado esse momento histórico, o marxismo, como teoria analítica, seria também superado.

Ainda conforme essas teses, a última reestruturação produtiva no Japão, Europa e Estados Unidos, com relativa diminuição de postos de trabalho na indústria e ampliação da produção de serviços, sobretudo, de trabalhos nos quais predominariam o conhecimento e a informação, se caracterizaria como a expressão concreta do fim desse estágio produtivo industrial e como começo de um novo estágio caracterizado pela produção de serviços.

Assim, o esgotamento da produção tipicamente industrial, marcado por um longo período que vai do século XVIII à década de 1970, teria desencadeado um conjunto de preocupações teóricas para essa "nova" sociedade que se estruturaria nos escombros da sociedade dita industrial. Esse é o diagnóstico do sociólogo estadunidense Daniel Bell (1977). Para o autor, o conhecimento produzido nas universidades e centros de pesquisa seria o novo eixo de sociabilização das sociedades "pós-industriais". As "sociedades industriais" estariam agora restritas aos países do "terceiro mundo" que, se seguirem a receita dos países desenvolvidos ou "pós-industriais", tenderiam a atingir esse estágio baseado na produção de conhecimento. A produção imediata de mercadorias tornar-se-ia uma esfera secundária da vida social em relação àquelas situadas fora dela, sendo que “(...) 0 problema de maior relevância (...) [seria] a organização da Ciência, e a instituição primordial a universidade ou o instituto de pesquisa onde se leva adiante esse trabalho" (BELL, 1977, p. 138).

Em termos distintos, mas ancorado na mesma problemática de superação do paradigma produtivo, Alain Touraine $(1970 ; 1989)$ indica a necessidade de revisão das formas de luta orientadas por "antigos movimentos sociais" (sindicatos e partidos) e observa a presença de "novos movimentos sociais" localizados na esfera da sociedade civil.

A presença desses "novos movimentos sociais" se fundamentaria como expressão de conflitos que não seriam mais determinados pela indústria, pelo trabalho assalariado, pela luta sindical e partidária, isto é, pela economia 
estrito senso, mas que estariam generalizados por todas as sociedades que, no entendimento de Touraine, também seriam "pós-industriais". Nessas sociedades, os conflitos adviriam da luta por uma maior participação na esfera política e cultural, contra as novas formas de dominação, agora de cunho "tecnocrático", ou seja, pela apropriação e retenção de informações estratégicas à sua administração4. 0 conflito deveria ser introduzido e reconhecido em todos os domínios da vida social, e particularmente ao nível da organização social e cultural. Os "novos movimentos sociais" se localizariam, desse modo, no campo da cultura, da sociabilidade, do modo de vida, dos valores, da identidade de minorias, não se caracterizando por lutas pela igualdade, mas pelo direito à diferença. Estariam deslocados do terreno meramente produtivo, não respondendo, portanto, a um conflito estrutural entre classes sociais opostas. ${ }^{5}$

Claus Offe (1989), compartilhando da mesma perspectiva de Touraine, realiza uma leitura das sociedades capitalistas depois da última reestruturação produtiva. Relaciona a redução das taxas de sindicalização ao consequente enfraquecimento da ação política da classe trabalhadora, evidenciando sua fragmentação como fruto da heterogeneidade profissional dos trabalhadores no setor de serviços. Haveria, segundo o autor, um deslocamento do número de postos de trabalho da indústria para os serviços que implicaria em uma nova forma de organização de resistência fora dos laços do trabalho. 0 cenário de refundação e reconstituição da luta política coletiva passaria, nesses termos, a ser a sociedade civil onde os novos movimentos sociais se articulariam com base em lutas ditadas por valores universais como, por exemplo, a paz, o meio ambiente e os direitos humanos, dos quais participariam os vários estratos da sociedade capitalista.

Já para André Gorz (1987), as sociedades capitalistas teriam vencido a batalha contra o socialismo real dando fim a um período dominado politicamente

\footnotetext{
${ }^{4}$ A partir da crítica à tecnocracia surgem as discussões acerca das "novas classes médias", isto é, aquelas vinculadas especialmente às atividades de gestão e burocracia (escritório). Este corpo técnico-administrativo foi concebido por vários estudiosos do trabalho, de orientação weberiana, particularmente no contexto do modelo de Estado de bem-estar social, como uma classe intermediária, com valores e interesses próprios cujos conflitos extrapolariam o âmbito da produção e girariam em torno da manutenção e ampliação dos privilégios legados pelo padrão fordista de mercado de trabalho. A estes argumentos somaram-se os do fim da centralidade do trabalho, e contribuíram para se retirar de pauta as reflexões concernidas às classes do campo das ciências sociais (Cf. WOLFF e CAVALCANTI, 2008).

${ }^{5}$ Como sugere inadvertidamente Touraine: "A classe popular não pode mais ser identificada como um novo tipo de dirigente. Descobrimos que os conflitos de classes não representam mais os instrumentos de mudanças históricas" (1989, p. 15).
} 
por lutas oriundas da indústria e de forte apelo sindical e partidário. A aposta na vanguarda operária, qualificada, ilustrada e bem paga e que, por isto, conduziria as lutas contra exploração e alienação na produção, teria sido perdida pela sua cooptação às vantagens e relativos privilégios conquistados neste mesmo espaço, e reverberados na esfera do consumo (AMORIM, 2006). As formas da produção, assim, teriam deslocado seu eixo do trabalho imediato para setores administrativos e de serviço, corroborando a ideia tourainiana de que a nova fonte de conflitos seria a apropriação da informação e não do mais-trabalho. Gorz deu, assim, adeus ao proletariado e à luta política coletiva que estaria, para ele, vinculada apenas à industria. Sua análise propôs uma sociedade dualista e resignada ao espaço da heteronomia (produção de mercadorias) e ao espaço da autonomia (liberdade subjetiva), muito embora não tenha deixado claro como seria possível conciliar tal autonomia em uma sociedade ainda preponderantemente produtora de mercadorias ou heterônoma. ${ }^{6}$

Ainda segundo Gorz, a impossibilidade de superação da produção capitalista de mercadorias imporia a necessidade de constituição e apropriação de espaços de liberdade que não estivessem tomados pela racionalidade econômica oriunda da indústria. Seria nos interstícios da sociedade vigente que se fundamentaria a liberdade e a ação coletiva (1987, p. 12). Com isso, na sociedade civil se encontrariam os recursos para a formação de um sujeito político distinto do proletariado industrial indicado por Marx como sujeito universal. Formados por um conjunto de indivíduos radicalmente heterogêneos "a não-classe dos não-trabalhadores" (1987, p. 17) aglutinaria, fora do trabalho, as características necessárias para a formação de uma luta política coletiva oposta à dos antigos movimentos sociais e que teria como objetivo central a ampliação de espaços de liberdade que refreassem o desenvolvimento da racionalidade burguesa ${ }^{7}$.

Mais tarde, Habermas (1987a) consubstanciou essas ideias, dandolhes um corpo teórico-metodológico mais lato, ao redefini-las como mundo do

\footnotetext{
${ }^{6}$ Gorz (1988, p. 36) redefiniu essa distinção em "tempo de trabalho" e "tempo de vida", o que Jürgen Habermas (1987a), posteriormente, denominou de "sistema" e "mundo da vida".

7 "Essa não-classe engloba, na realidade, o conjunto dos indivíduos que se encontram expulsos da produção pelo processo de abolição do trabalho, ou subempregados em suas capacidades pela industrialização (ou seja, pela automatização e pela informatização) do trabalho intelectual. Engloba o conjunto desses extra-numéricos da produção social que são os desempregados reais e virtuais, permanentes e temporários, totais e parciais. É o produto da decomposição da antiga sociedade fundada no trabalho: na dignidade, na valorização, na utilidade social, no desejo do trabalho" (GORZ, 1987, p. 88).
} 
trabalho e mundo da vida. Para o autor, o mundo do trabalho é o mundo da racionalidade instrumental, que orienta as ações de cunho estratégico, ou seja, aquelas permeadas pela busca do lucro e/ou qualquer outro tipo de vantagem de ordem pessoal. 0 mundo do trabalho seria o sistema (no sentido parsoniano), pois referido ao dinheiro e ao mercado capitalista moderno. 0 mundo da vida teria uma ação anti-sistêmica diante da cada vez mais invasiva sistemática que conforma 0 sistema, na medida em que é orientado pela "ação comunicativa", isto é, aquela caracterizada pela reflexão, interpretação, e interesses coletivos democraticamente negociados com base na argumentação autônoma de todos os sujeitos envolvidos. Com efeito, uma sociedade seria tanto mais democrática quanto mais estabelecida pela ação comunicativa.

Na prática sociológica, o mundo da vida deveria reorientar o seu objeto a favor daquilo que seria o seu lócus por excelência, isto é, os novos movimentos sociais (HABERMAS, 1987b), cujas reivindicações não só passam ao largo daquelas concernidas ao mundo do trabalho, mas que, por isto mesmo, têm a faculdade de atrofiar o "sistema" em prol da ação comunicativa. Com isto, acrescenta-se mais um conveniente e sedutor argumento teórico às teses do fim da centralidade do trabalho ao se descredenciar as reivindicações postuladas no mundo do trabalho, que seriam demasiadamente herméticas e unívocas, em prol daquelas localizadas no mundo da vida, mais plurais e trans-classes. Por suposto, como afirmaria Offe (1989, p. 20) cujos "temas conflituais são, em certa medida, confrontados pela esfera da produção a partir de fora, onde frequentemente encontram a resistência unificada tanto do trabalho como do capital".

Nasociologia brasileira as teses sobre a ineficácia da teoria marxista das classes teve forte impacto. Tanto autores de tradição marxista quanto fora do marxismo foram influenciados pela conjuntura político-econômica que se anunciava durante e ao final da década de 1970 (com o desmantelamento da União Soviética, 0 crescimento de políticas neoliberais, a reestruturação produtiva e crescimento do setor de serviços, sobretudo, aquele vinculado à produção de bens intangíveis).

0 mainstream da sociologia brasileira passa, a partir dos anos 1980, a importar as teses européias e estadunidenses que se fundamentam na relevância dos serviços e dos atores políticos variados na sociedade civil em função da estagnação da indústriå. No entanto, essa absorção se dá sem que a sociedade brasileira tenha passado pelas mesmas experiências históricas que os países nos quais essa indicação problemática foi desenvolvida.

${ }^{8}$ É neste último ponto, particularmente, que se encontra clara influência das teorias habermasianas. 
No Brasil, o movimento operário, sindical e partidário ligado à classe trabalhadora cresceu vigorosamente ao final de 1970 e durante a década de 1980, evidenciando um conjunto de ideias evidentemente fora do lugar. As greves de 1978-80 no ABC em São Paulo, a formação do Partido dos Trabalhadores (PT) em 1980, a campanha das diretas já e o processo de democratização política promovido durante a década de $1980^{\circ}$ são expressão da luta política concreta que para o modismo europeu passou a ser denominada como "antigos movimentos sociais" ou "movimentos sociais tradicionais", caracterizado como uma fase já ultrapassada ou, pelo menos, em vias de superação.

Um exemplo da absorção das teses européias está na discussão proposta por Cardoso (1982) sobre a nova configuração das classes nas sociedades contemporâneas. Ainda partindo da problemática das classes sociais, Cardoso relativiza argumentos desenvolvidos na década anterior, passando a dar maior atenção a outras esferas sociais supostamente novas e desvinculadas da produção de mercadorias. ${ }^{10}$ Seu diálogo se desenvolve, sobretudo, com Bell (1977) e Touraine (1970) promovendo, assim, a inserção das teses desses autores no cenário sociológico brasileiro.

Argumentos que reduzem a análise marxista ao campo do econômico, limitando sua intervenção ao industrialismo, foram desenvolvidos nos anos 1990 no Brasil, tomando Offe (1989) e Habermas (1987a; 1987b) como referências centrais. Waizbort, por exemplo, realiza uma leitura enviesada da obra de Marx e questiona em que medida as sociedades contemporâneas seriam as mesmas que Marx havia presenciado no século XIX, a partir das seguintes interrogações: "é a classe, hoje, definidora de identidades coletivas? Em que medida, ou até aonde? Não foram as classes enfraquecidas na sua qualidade de definidoras por excelência de identidades coletivas?" (1998, p. 67). Para ele, haveria uma diferença substancial entre a organização social no século XIX e no XX, já que as sociedades contemporâneas atingiram um nível de desenvolvimento econômico e de planejamento muito avançado em relação ao século XIX. Apesar da permanência do desemprego ser um índice indicativo da continuidade do conflito instaurado pela oposição entre capital e trabalho, o trabalho não seria mais a atividade central da sociedade capitalista como o fora anteriormente: "Na estrutura e no processo da

\footnotetext{
${ }^{9}$ Sobre esse contexto ver: Antunes (1992); e Rodrigues (1997).

${ }^{10}$ Para Cardoso, mesmo admitindo o peso do capital "é preciso insistir em que estas formas e especialmente a 'politização' da produção e da repartição do produto criaram novos tipos de sociedade e abriram novas vias de luta mais generalizadas e mais diversificadas, para as várias categorias sociais." (1982, p. 28).
} 
sociedade, o trabalho e os trabalhadores não surgem mais, como antes, como um princípio fundamental que 'ordena' ou 'determina' ou 'organiza' a sociedade" (WAIZBORT, 1998, p. 71).

Mais uma vez o argumento levantado por Waizbort gira em torno das taxas de industrialização e do número de empregos na indústria. Nas estatísticas expostas, 0 autor indica a presença de apenas 10\% da população ativa empregada no setor secundário no final do século XX. A absorção desse outro contingente ativo pode ser parcialmente realocada nos serviços. No entanto, o autor afirma serem esses empregos de baixíssima qualificação e remuneração, concluindo, portanto, que o trabalho como atividade sociabilizadora se tornou opaco. Haveria, assim, uma perda de laços sociais no trabalho e a constituição de identidades coletivas com base no trabalho seria cada vez mais difícil de ser observada.

A indicação do fim das classes sociais e do esgotamento da teoria marxista, reduzida a uma teoria do industrialismo traz consigo, portanto, alguns questionamentos de fundo. Qual seria o sentido das afirmações que pretendem superar a teoria das classes sociais? Seria um devaneio pós-moderno ou uma capitulação de intelectuais de esquerda que enfim teriam cedido à ideologia burguesa? Quais os fatos históricos concretos que orientam essas indicações?

A argumentação sobre a não validade analítica das teses de Marx sobre as classes sociais nos parece estar circunscrita a uma interpretação histórica, porém equivocada, do processo de reorganização espacial da indústria no mundo. Ou seja, ao limitar a análise de Marx à indústria se pressupõe 1. que a industrialização no mundo estaria em declínio e 2. que novas teorias, não marxistas, deveriam dar conta desse momento histórico diverso.

Nosso objetivo é, nesse momento, responder a falsa pressuposição que atesta um declínio industrial em detrimento do crescimento do setor de serviços. Para nós, este ponto de vista parte de análises que perspectivam o centro do capitalismo, isto, países da Europa, Estados Unidos e Japão. Nesse sentido, mostra-se fundamental a caracterização histórica de outros países quanto à relação entre setor secundário e terciário. Temos a intenção de debater, dentro da problemática do fim das classes, o equívoco em afirmar o esgotamento da indústria de bens materiais como eixo da produção de valor nas sociedades contemporâneas. Feito isso, seria importante superar essa problemática reducionista e economicista para ascender a uma nota indicativa sobre a análise das classes sociais e sobre o trabalho assalariado como conjunto de relações sociais centrais para a reprodução do modo de vida burguês. 
Nos indicadores estatísticos sobre o processo de industrialização da China e Índia, notamos o equívoco do diagnóstico baseado na diminuição de postos de trabalho ligados ao setor secundário. Segundo dados do Banco Mundial, a China e Índia apresentam um perfil semelhante de crescimento em relação à indústria. A Índia passou de 20\% para 28\% do PIB no período de 1960-2008 e a China de 37\% para $47 \%$ do PIB no mesmo período no que concerne ao crescimento da indústria. 0 setor de serviços acompanha esse cenário crescendo na China 8,7\% e na Índia 5,8\% no mesmo período.

Se na Europa, Estados Unidos e Japão a classe operária perdeu e continua a perder postos de trabalho na indústria, isto se deve, muito mais, a uma tentativa do capital em se valorizar internacionalmente, isto é, fora de sociedades em que há uma relativa valorização da força de trabalho (fruto de lutas e conquistas históricas da classe trabalhadora) em comparação a países de industrialização recente do que por conta de uma suposta crise da produção industrial.

Neste sentido, uma análise restrita aos países de economia avançada faz apenas explicitar a aparência da economia-política capitalista hoje, isto é, uma falsa projeção. A produção de bens duráveis continua a participar decisivamente da organização social e do fluxo de capitais no mundo. Seria no mínimo duvidoso indicar a presença de sociedades pós-industriais nas quais prevaleceriam bens imateriais, como expressão sintética das sociedades capitalistas.

Não obstante, essa primeira indicação dentro do que foi denominado como paradigma produtivo é limitada e não qualifica teoricamente nossa discussão. 0 primeiro ponto decisivo para o debate deveria, contrariamente, indagar: a análise marxista das classes sociais tem a esfera econômica como central? Ela seria uma análise restrita à indústria? Ou seria uma análise sobre a história social do modo de vida burguês?

Não será aqui que responderemos de forma mais sistemática a essas questões. No entanto, de início é preciso separar a análise de Marx das classes sociais, exposta em livros como o Dezoito Brumário de Luís Bonaparte, de o Capital e do Manifesto do Partido Comunista, por exemplo, da análise e da política dos partidos comunistas, sob orientação do partido comunista soviético até os anos 1970.

A orientação geral sobre as classes sociais e mais especificamente sobre a classe operária e, potencialmente revolucionária, dos PCs se restringe ao lugar que o indivíduo ocupa no processo de produção de mercadorias. De imediato notamos o limite dessa definição a um terreno caracterizado como estritamente 
econômico. Nesse sentido, as teorias críticas ao paradigma produtivo o associaram a esse tipo de marxismo e conclamaram seu fim.

Tal concepção restrita de classe social tem, a nosso ver, pelo menos dois problemas. Primeiro, ela confere ao posto de trabalho, ou seja, à categoria profissional, e, por extensão, à qualificação profissional um peso desmedido. Segundo, o conjunto de relações sociais que, como resultado concreto, constitui as formas de exploração e dominação específicas no processo de trabalho é identificado como partes constitutivas de indivíduos isolados. Com base na distinção entre trabalhadores produtivos e improdutivos, tornou-se tarefa simples aos partidos comunistas identificar aqueles pertencentes ou não à classe operária e tomá-los como sujeitos históricos da revolução socialista ${ }^{11}$, transformando a classe social em um conceito positivista que limita sua definição a um conjunto enumerável de indivíduos dispostos em funções profissionais.

Sugerimos, destarte, dois princípios de leitura das classes sociais em Marx. Primeiro, nos parece que a lógica do capital tem, nos aspectos que são identificados usualmente como econômicos, sua síntese. ${ }^{12}$ Não obstante, é, para nós, impossível a apreensão dessa "esfera" em sentido isolado. A "esfera da economia" não é senão uma construção teórica sobre uma realidade que precisa ser recortada teoricamente para ser, talvez, reconstruída politicamente. Não há, assim, o "econômico", o "político", o "ideológico" em sua forma isolada e pura. A síntese governada pelo capital na figura do econômico, na relação produçãocirculação de mercadorias, é expressão de uma síntese de elementos variados que ganham apenas a aparência de econômica.

Portanto, analisar as representações do econômico como movimento geral do capital obscurece as relações sociais que fundam e reproduzem a exploração e a dominação social. 0 capital como relação social hegemônica no capitalismo transcende a matéria física das coisas, o conteúdo formal de relações econômicas, ou de qualificações profissionais. Neste sentido, é um modo de vida, uma forma de existência que só pode ser dividida teoricamente, em um primeiro momento pelo conhecimento como processo metodológico para, no segundo, ser reconstruído como práxis. A particularização de sua existência observada deve, assim, ser reconstruída em uma teoria política.

\footnotetext{
${ }^{11}$ Bensaïd faz alusão a essa questão, mostrando como os PCs se utilizavam ideologicamente de uma concepção restrita de classe operária (AMORIM; GALASTRI, 2010).

${ }^{12}$ Ver Marx (1996).
} 
0 segundo princípio tem relação com a análise que Marx faz das classes sociais. Nas duas páginas finais de 0 Capital, Marx propõe uma leitura da aparência da estrutura capitalista, indicando a presença de três grandes classes sociais: a capitalista, a assalariada e a dos proprietários de terra, e nos lança 0 problema: "À primeira vista, a identidade de rendimentos e as fontes de rendimento. São três grandes grupos, cujos componentes, os indivíduos que os formam, vivem respectivamente de salário, lucro e renda fundiária" (1988, p. 297). Ou seja, do ponto de vista que leva em consideração apenas a posição do indivíduo no processo de produção, reduzindo essa posição ao plano do econômico, as classes sociais seriam reduzidas a estratos sociais, podendo ser definidas com base na renda, status, mérito, qualificação profissional, etc. etc.

No entanto, esse não é o fundamento de sua análise. Definindo negativamente as classes sociais Marx ironiza: “(...) Desse ponto de vista, [de uma definição de classe social baseada na renda ou na profissão] no entanto, médicos e funcionários públicos, por exemplo constituíram duas classes, pois pertencem a dois grupos sociais diferentes, em que os rendimentos dos membros de cada um deles fluem da mesma fonte. 0 mesmo seria válido para a infinita fragmentação de interesses e de posicionamentos em que a divisão do trabalho social separa tanto os trabalhadores quanto os capitalistas e proprietários de terra" (1988, p. 298).

Diante dessas indicações o melhor seria nos voltarmos à realidade empírica e verificar a presença de relações de classes nas sociedades contemporâneas, o que, para além de divagações sobre a inoperância, a não validade e a caducidade da análise marxista das classes nos forneceria elementos concretos de análise social. Não obstante, podemos aqui reter o conceito de classe social, como uma abstração concreta, como um mecanismo de análise das relações sociais em formações sociais distintas, que explicita os edifícios fundamentais da estrutura capitalista como a organização do Estado do governo, dos partidos, dos sindicatos, da escola, dos movimentos sociais. Ou seja, de como uma sociedade é constituída e com base em quais interesses políticos ela opera.

Os artigos que compõem este Dossiê não coincidem exatamente com as ponderações feitas nessa apresentação, mas antes encerram uma pluralidade de argumentos que compõem o universo de relações sociais classistas tanto em termos empíricos, quanto no que concerne à atualização da problemática das classes sociais e do trabalho na atual fase do capitalismo. Neste sentido, contribuem para o diagnóstico das múltiplas formas de precarização e superexploração do trabalho, da flexibilização das relações e leis trabalhistas, e do consequente aprofundamento da desigualdade social e das lutas sociais que assistimos na contemporaneidade. 
Abrimos o Dossiê com um texto de Ursula Huws questionando a ideologia informacional, que vem na esteira das transformações que a globalização da economia trouxe para as relações entre capital e trabalho. Tributária das teses da sociedade "pós-industrial", já aludidas nesta Apresentação, é dessa ideologia que emergem conceitos tais como economia e trabalho imaterial, que concebem um mundo no qual o conhecimento seria a única fonte do valor. Ao recolocar a chamada "economia imaterial" do espaço cibernético na materialidade do mundo do capital, a autora produz atualiza e realiza uma profícua crítica a esses postulados.

Paula Marcelino faz uma acurada pesquisa bibliográfica dos estudos do trabalho, decupando os termos "flexibilização" e "precarização", "trabalho atípico" e "desregulamentação". A autora analisa quais as maneiras mais adequadas de combinar o uso ou não destes termos com as situações efetivamente vivenciadas pelos trabalhadores no capitalismo contemporâneo.

Para examinar os elementos que constituem a "classe social do proletariado", Giovanni Alves e Esdras Selegrin questionam o enfoque analítico marxista que trata classe como um dado sócio-estrutural. Para eles, é preciso lidar com o proletariado como um sujeito histórico-coletivo, que se faz "visível ou invisível" conforme determinadas condições históricas, reiterando o enfoque relacional, aqui sustentado, para o entendimento dessa questão.

Nilo Pereira Netto e Nanci Stancki daLuzfazem uma revisão do debate acerca da divisão sexual do trabalho, apontando a necessidade de compreender o trabalho feminino como fundamento da precarização da sociabilidade contemporânea. Relendo importantes estudos dialéticos sobre o trabalho, os autores localizam o papel da mulher delegado pela flexibilidade do capitalismo atual.

Geraldo Augusto Pinto e Carolina Kemmelmeier tratam das transformações do Direito do Trabalho no Brasil a partir da década de 1990. Com foco de análise na maneira pela qual os governos federais alavancaram formas de organização flexível do trabalho, os autores esclarecem como estas metamorfoses legislativas foram ao encontro dos interesses de oligopólios de corporações privadas transnacionais.

0 texto de Helaynne Faria e Maristela Dalbello-Araujo aborda o processo de produção do cuidado em saúde, revelando as relações entre a precarização, via terceirização, das relações de trabalho no campo da saúde e atendimento à população, que acaba por afetar negativamente o fornecimento deste tipo de serviço.

Com o escopo de apontar os limites da educação para o trabalho dentro do capitalismo, Rafael Toitio recupera a temática marxiana da subsunção do trabalho ao capital, para apresentar a relação entre a revolução da microeletrônica e a formação dos trabalhadores. 
0 artigo de Magda Biavaschi e Alisson Droppa faz um trajeto histórico acerca do entendimento do Judiciário do Trabalho brasileiro no que concerne à terceirização e à responsabilização da tomadora dos serviços, através da revisão do Enunciado 256 do TST, que trata da prestação de serviços. Mediante análise da Súmula 331, os autores conseguem compreender as transformações operadas no Tribunal Superior do Trabalho em meio à atual reestruturação produtiva.

A partir de uma recuperação histórica rigorosa, Luciana Wollmann traça um percurso dos antigos trabalhadores da Cia. Fluminense de Tecidos de NiteróiRJ, com o objetivo de analisar as identidades de classe destes operários. A autora delineia a persistência da identificação dos operários com seu trabalho, mesmo após a decadência da fábrica.

Augusto Neftali Oliveira faz um panorama da representação política da classe trabalhadora latino-americana durante os anos 2000. Utilizando uma interessante metodologia de pesquisa, o autor consegue trazer ao leitor parâmetros que definem programaticamente 19 partidos de esquerda de 15 países da região, no período delimitado.

Por fim, apresentamos o artigo de Alexandre Soares que trata da juventude trabalhadora da periferia carioca. 0 autor dá relevo às representações do confinamento, tanto urbano quanto no (não)trabalho, a que os jovens estão submetidos em um contexto de desemprego galopante, instabilidade e deterioração do mercado laboral.

Esperamos que a leitura dos artigos em tela possa fornecer um panorama variegado das transformações por que passa a classe trabalhadora, e venha a contribuir não só para um maior entendimento destas questões como também ofereça novas reflexões e ferramentas analíticas para se pensar a superação do quadro de precariedade que estamos a enfrentar.

\section{REFERÊNCIAS}

AMORIM, Henrique; GALASTRI, Leandro. Teoria do valor, trabalho e classes sociais: Entrevista com Daniel Bensaïd. Revista Crítica Marxista, n. 30, São Paulo/UNESP, 2010, p. 89-102.

AMORIM, Henrique. Teoria social e reducionismo analítico: para uma crítica ao debate sobre a centralidade do trabalho. Caxias do Sul-RS: Educs, 2006.

ANTUNES, Ricardo. A Rebeldia do Trabalho: o confronto operário no ABC paulista (as greves de 1978/80). São Paulo: Editora da Unicamp, 1992. 
BELL, Daniel. O Advento da Sociedade Pós-Industrial: uma tentativa de previsão social. São Paulo: Cultrix. 1977.

CARDOSO, Fernando Henrique. As classes sociais nas sociedades capitalistas contemporâneas (notas preliminares). Revista de Economia Política, vol. 2/1, n. 5, São Paulo, jan./mar., 1982, p. 7-20.

. Althusserianismo ou Marxismo: A propósito do Conceito de Classes em Poulantzas: Comentários. Estudos CEBRAP, vol. 3, n.3, São Paulo, 1973, p. 65-85 GORZ, André. Adeus ao Proletariado - Para Além do Socialismo. Rio de Janeiro: Forense, 1987.

. Métamorphoses du Travail. Quête du Sens: critique de la raison economique. Paris: Galilée, 1988.

HABERMAS, Jürgen. Teoría de la Acción Comunicativa. Madrid: Taurus, 1987a, p. 103-114.

A nova intransparência: a crise do Estado de bem-estar social e 0 esgotamento das energias utópicas. Novos Estudos CEBRAP, n. 18, São Paulo, set.1987b.

MARX, Karl. \& ENGELS, Friedrich. Manifesto do Partido Comunista. Petrópolis: Vozes, 1996.

. 0 método da Economia Política. Primeira Versão. Campinas, IFCH/ Unicamp, 1996.

. 0 Capital. São Paulo: Nova Cultural, livro III, vol. V, tomo 2, 1988.

OFFE, Claus. Trabalho: a categoria-chave da Sociologia? RBCS, n.10, v.4, São Paulo, junho/1989, p. 6-20.

RODRIGUES, Iram Jácome. Sindicalismo e política — a trajetória da CUT. São Paulo, Scritta/FAPESP, 1997.

TOURAINE, Alain. Os novos conflitos sociais: para evitar mal-entendidos. Lua Nova, n.17, São Paulo, 1989, p. 5-18. . Sociedade Pós-Industrial. Lisboa: Moraes Editores, 1970.

WAIZBORT, Leopoldo. Classe Social, Estado e Ideologia. Tempo Social, vol. 10, n.1, São Paulo, USP, maio. 1998, p. 65-81.

WOLFF, Simone; CAVALCANTE, Sávio M. Os gerentes na empresa neoliberal e a crise das classes médias. Anais $32^{\circ}$ Encontro Anual da ANPOCS, 27 a 31 de outubro, Caxambu, MG, 2008. 